it is disturbing to find the absence of any programmed activity for two fifths of the hospital patients studied by Oliver et al, despite the amount of publicity given to these hospitals in recent years. Self injury carries a serious risk of permanent damage, such as subdural haemorrhage, blindness, or deformity-or even death-and hence not surprisingly patients are treated with tranquillisers and different forms of physical restraint. ${ }^{6}$ Thus no fewer than two thirds of the hospital patients in this study were receiving psychotropic drugs, usually long term; many were also wearing protective devices.

As the authors of this survey emphasised, skills may be lost as a result of the long term use of physical restraints ${ }^{6}$ and drugs are ineffective for treating self injurious behaviour. ${ }^{7}$ Only 12 of their 596 patients had had written psychological programmes to correct their abnormal behaviour, yet these are known to provide the most effective treatment possible, by providing alternative stimulation and activity as well as positive reinforcement of normal behaviour. ${ }^{8}$ Unfortunately there is still a grave shortage of people trained in using these methods for treating the distressing problem of self injury.

BRIAN KIRMAN

Retired Consultant Psychiatrist,

London SW16 2HS

1 Bicknell DJ. An investigation into the aetiology and ill effects of pica in childhood. In: Clayton BE, ed. Mental retardation: environmental hazards. London: Butterworth, 1973:89-107.

2 Kirman BH, Bicknell DJ. Congenital insensitivity to pain in an imbecile boy. Dev Med Child Neurol 1968;10:57-63.

3 Lesch M, Nyhan WLA. A familial disorder of uric acid metabolism and central nervous system function. Am J Med 1944;36:561-70.

4 Shear CS, Nyhan WL, Kirman BH. Self-mutilating behaviour as a feature of the De Lange syndrome. $f$ Pediatr 1978;78:506-9.

5 Oliver C, Murphy GH, Corbett JA. Self-injurious behaviour in people with mental handicap: a total population study. F Ment Defic Res (in press).

6 Spain B, Hart SA, Corbett J. The use of appliances in the treatment of self-injurious behaviour. In Murphy G, Wilson B, eds. Self-injurious behaviour. Kidderminster: BIMH Publications, 1985.

7 Williams DE, Weir HF, Hargrave RL, Parker CM, Marek K. Effects of a facility-wide psychoactive drug evaluation behaviour management system. In: Griffin JC et al, eds. Advances in the treatment of self-injurious behaviour. Austin, Texas: Planning Council for Developmental Disabilities, 1984

8 Murphy G, Wilson B. Self injurious behaviour: a collection of papers on prevalence, causes, and treatment in people who are mentally handicapped or autistic. Kidderminster: BIMH Publications, 1985.

\section{From Vesalius to telefax: 100 years of the BMA library}

Everything changes, wrote Gertrude Stein, but not without a reason. Medical journals of 100 years ago certainly had a different style from now-"Before coming to facts, I should like to give expression to some thoughts which have been floating in my mind," wrote Angel Money, starting an original article in the $B M F$ in 1887 . What is most surprising, however, is how few references were cited: entire journals then had fewer references than does today's average paper, which is why medical libraries are now so important.

In the typical paper of a century ago one man shared the wealth of his experience with all who might care to benefit from it. Many papers started life as speeches, and at their worst they had the tone of a bar room bore haranguing the customers. Before sitting down to write today's doctors consult "the literature," in some cases everything that has been written on their subject. Papers now resemble animated conversations: other points of view are considered and rebutted or accepted. Messages, sometimes explicit, sometimes coded, are sent out to other workers. Monologue is out. In place of one man and his dogma we have the chat show.

To join in the conversation means having access to others' opinions, and as no one person or department can afford subscriptions to all the relevant journals this presupposes a library. It is the medical library that allows the conversation to take place. Given this it seems surprising that an association committed to the diffusion and increase of medical knowledge could still have no library 50 years after its formation. A committee of the Provincial Medical and Surgical Association (the BMA's precursor) looked into the possibility of establishing a library in 1834 but decided against it on three main grounds: the expense, the space required, and the problems of access for its members.

Nothing happened until 1887, when Ernest Hart, then editor of the $B M F$, recommended to the council of the BMA that a library should be formed and offered to start it with a collection of his own books (including Vesalius's De Humani Corporis Fabrica). He became the library's first librarian and pledged books sent to the journal for review and arranged to exchange the $B M \mathcal{F}$ with other journals (practices which continue today).

The library was such a transparently good idea that once started it has never looked back: its current holdings are of over 30000 books and 2000 sets of periodicals-over 1200 of which are currently taken. Another 23 databases are available for searches. Members of the BMA unable to visit the library may borrow books and request photocopies and searches by post. The libraries of over 200 postgraduate medical centres are institutional members of the library, allowing them to augment their limited stocks by calling on its resources. With Telecom Gold, mailbox (74: BMX030) messages can be left for the library at any time from anywhere in the world. Telefax (01 388 2544) provides a similar service but can also be used to send photocopies of articles anywhere. As the movable type was to Vesalius's world so the microchip is to ours: it leaves the muscle men of the De Humani for dead.

Problems of access to the library's facilities for BMA members wherever they are seem finally to have been solved, and after spending much of its last 100 years on the move a suitable space may at last have been found for the library too. Abandoning the site where Charles Dickens lived from Bleak House to Great Expectations, the library ascended two years ago into what was designed by Sir Edwin Lutyens as a temple for the Theosophists.

Of the three problems mentioned by the committee of the Provincial Medical and Surgical Association in 1834 only the one of expense remains-and seems likely to do so. Otherwise, it makes no sense to predict what form the library's future will take. After all, 100 years ago Ernest Hart's view of library science was suitable shelving, and now their contents are whizzing through the ether at $\mathbf{1 8 6 0 0 0}$ miles a second.

Tony Delamothe

Assistant Editor, BMY .

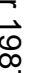

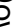

